\title{
STUDI ETNOFARMASI TUMBUHAN BERKHASIAT OBAT PADA SUKU BANGGAI DI KABUPATEN BANGGAI LAUT, PROVINSI SULAWESI TENGAH
}

\section{STUDY OF HERBS ETNOPHARMACY TO BANGGAI ETHNIC IN BANGGAI LAUT REGENCY, CENTRAL SULAWESI}

\author{
Nur Khairiyah $^{1^{*}}$, Syariful Anam ${ }^{1}$, Akhmad Khumaidi $^{1}$ \\ ${ }^{1}$ Jurusan Farmasi, Fakultas MIPA, Universitas Tadulako, Palu, Indonesia
}

Received 4 November 2015, Accepted 20 Februari 2016

\begin{abstract}
ABSTRAK
Studi etnofarmasi tumbuhan berkhasiat obat pada suku Banggai telah dilakukan dari bulan Maret sampai Juni 2015 di Kabupaten Banggai Laut, Sulawesi Tengah. Penelitian ini bertujuan untuk mengetahui berbagai jenis dan bagian tumbuhan yang dimanfaatkan sebagai obat tradisional, jenis-jenis penyakit yang diobati dan cara pemanfaatan tumbuhan obat oleh suku Banggai di Kabupaten Banggai Laut. Jenis penelitian ini adalah penelitian deskriptif yang menggunakan metode kualitatif dan teknik pengambilan sampel yakni purposivesampling melalui wawancara open-ended interview dengan 7 informan yangmenggunakan media angket kuesioner. Berdasarkan hasil penelitian diketahui sebanyak 54 spesies tumbuhan dan terbagi dalam 31 familia yang dimanfaatkan sebagai obat. Tumbuhan yang paling banyak digunakan yaitu dari familia Zingiberaceae dan familia Lamiaceae sebanyak 5 spesies.Berdasarkan hasil wawancara yang telah dilakukan, terdapat 10 macam penyakit kronik, 3 macam penyakit menular, 27 macam penyakit tidak menular dan 5 kegunaan untuk perawatan kesehatan tubuh. Bagian tumbuhan yang digunakan antara lain daun, batang, getah, buah, rimpang, akar, umbi, herba, dankulitbatang. Bagian tumbuhan yang paling banyak digunakan yaitu daun sebanyak 49\%. Cara pengolahan tumbuhan obat oleh suku Banggai di Kabupaten Banggai Laut yaitu direbus, ditumbuk, diremas, diperas, diparut, direndam, diseduh, dikonsumsi langsung dan cara penggunaan yang dilakukan yaitu diminum, dimakan, digosok, ditempelkan, dioleskan, dibalurkan dan langsung digunakan. Cara pengolahan yang paling banyak yaitu direbus dan cara penggunaan yang paling banyak yaitu diminum. Semakin tinggi kepercayaan masyarakat suku Banggai terhadap suatu tumbuhan untuk dapat menyembuhkan suatu penyakit maka semakin tinggi pula penggunaan masyarakat terhadap tumbuhan tersebut.
\end{abstract}

Kata kunci: Etnofarmasi, Tumbuhan Obat, Suku Banggai.

\begin{abstract}
A study of nutritious herbs etnopharmacy has been done to Banggai ethnic from March to June 2015 in Banggai Laut Regency, Central Sulawesi. This research aims at identifying every kind of herbs parts used as traditional medicine, types of diseases cured using herbs by Banggai ethnic in Banggai Laut Regency, and the percentage of the usage by the informant about herbs as a traditional medicine. This is a descriptive research that uses qualitative method and take the sample purposively through open-ended interview involved 7 informants asked by questionnaire. The result of this research revealed that there are 54 types of herbs divided into 31 family used as medicine. The most widely used herbs is from 5 species of Zingiberaceae family and Lamiaceae family. Interview result revealed that there are 10 types of chronic diseases, 3 infectious diseases, noncommunicable diseases 27 , and 5 used for health care body. The parts of herbs used are leaf (49 percent), stem, sap, fruit, rhizomes, roots, tubers, herbs and bark. The Banggai ethnic precede the herbs through boiled, mashed, squeezed, shredded, soaked, brewed and then consumed, drunk, rubbed, pasted, applied directly. Processing methods most often done is boiled and drunk the herbs straightly. The higher belief the society has in the herbs ability to cure the diseases the higher use of herbal medicine as an alternative of diseases healing.
\end{abstract}

Keywords: Etnopharmacy, Herbs, Banggai Ethnic

*Coresponding Author : Nurkhairiyah, nurkhairiyah18@gmail.com (ph: +62-852-4002-3886) 


\section{PENDAHULUAN}

Bangsa Indonesia telah lama mengenal dan menggunakan tanaman berkhasiat obat sebagai salah satu upaya dalam menanggulangi masalah kesehatan. Hampir setiap orang di Indonesia pernah menggunakan tumbuhan obat untuk mengobati penyakit dan diakui serta dirasakan manfaat tumbuhan obat ini dalam menyembuhkan penyakit yang diderita. Di seluruh wilayah nusantara, berbagai suku asli yang hidup di sekitar hutan telah memanfaatkan berbagai spesies tumbuhan untuk memelihara kesehatan dan pengobatan berbagai macam penyakit. Namun proses pewarisan pengetahuan lokal obat tradisional banyak dilakukan secara oral dan masuknya budaya modern ke masyarakat tradisional dikhawatirkan akan menyebabkan pengetahuan lokal akan hilang. Hal ini mendorong upaya pelestarian pengetahuan lokal obat tradisional sedini mungkin. Salah satunyadengan menggunakan pendekatan etnofarmasi (Bodeker, 2000).

Selain suku kaili (Dianto, 2015), salah satu suku di Sulawesi Tengah yang masih memanfaatkan tumbuhan untuk pengobatanadalah suku Banggai. Masyarakat suku Banggai masih menghargai budaya dan tata nilai leluhur yang dikembangkan secara turun temurun. Budaya masyarakat Banggai masih berkaitan dengan unsur keagamaan dan peranan Tuan, Guru/Kyai dan Pendeta merupakan figur/tokoh yang masih sangat dihormati masyarakat dalam berbagai bidang termasuk bidang kesehatan. Masyarakat suku Banggai secara turun-temurun telah mengenal pemanfaatan tumbuhan untuk kehidupan sehari-hari, selain digunakan sebagai ramuan obat, digunakan pula untuk bahan pangan dan dalam berbagai upacara adat. Masyarakat suku Banggai percaya bahwa keuntungan penggunaan tumbuhan yang digunakan sebagai obat dapat menyembuhkan berbagai macam penyakit dan tidak menimbulkan efek samping bagi pemakainya.

Akhir-akhir ini penelitian tentang pengetahuan dan pemanfaatan tumbuhan obat oleh masyarakat lokal telah banyak dilakukan di Indonesia. Namun, penelitian tentang etnofarmasi tumbuhan obat oleh suku Banggai di Kabupaten Banggai Laut belum pernah dilakukan, walaupun upaya kesehatan melalui penggunaan obat tradisional dari tumbuh-tumbuhan ini telah dikenal masyarakat suku Banggai dari dulu kala hingga saat ini. Oleh karena itu perlu dilakukan studi etnofarmasi pada suku Banggai di Kabupaten Banggai Laut, guna kepentingan dalam bidang kesehatan dan pengembangan ilmu pengetahuan.

\section{METODE PENELITIAN Jenis Penelitian}

Jenis penelitian ini adalah penelitian deskriptif yang menggunakan metode kualitatif. Metode kualitatif digunakan untuk mengetahui penggunaan tumbuhan yang digunakan oleh masyarakat suku Banggai di Kabupaten Banggai Laut sebagai obat.

\section{Waktu dan Tempat Penelitian}

Penelitian ini dilakukan sejak pada bulan Maret sampai Juni 2015, di Kabupaten Banggai Laut, Provinsi Sulawesi Tengah.

\section{Pemilihan Sampel (Informan)}

Teknik pengambilan sampel yang digunakan dalam penelitian ini yaitu purposive sampling. Sampel yang dipilih yaitu dengan pertimbangan tertentu, dalam hal ini orang yang dianggap paling tahu tentang tumbuhan obat melalui pertimbangan data Dinas Kesehatan Kabupaten Banggai Laut dan Kepala Desa (Sugiyono, 2007).

\section{Interview Informan}

Informasi dari Informan (sandro) didapatkan melalui wawancara semistructured. Teknik wawancara dilakukan dengan menggunakan tipe pertanyaan openended interview (Nototamodjo, 2002). Tahap pertama dari studi lapangan yang dilakukan, para informan ditanya tentang tumbuhan yang digunakan sebagai bahan baku obat, bagian tumbuhan yang digunakan, cara penggunaan dan cara pengolahan tumbuhan serta jenisjenis penyakit yang diobati, dengan menggunakan media angket kuesioner.

\section{Pengumpulan Spesimen}

Pengumpulan spesimen dilakukan langsung pada lokasi tumbuhnya dengan dibantu oleh informan. Spesimen dikoleksi dan didokumentasikan kemudian diidentifikasi di UPT Sumber Daya Hayati Sulawesi, Universitas Tadulako. 
HASIL DAN PEMBAHASAN

Hasil

Berdasarkan hasil identifikasi spesimen yang dilakukan di UPT Sumber
Daya Hayati Sulawesi Universitas Tadulako didapatkan sebanyak 31 famili tumbuhan yang terdiri dari 54 jenis tumbuhan obat yang digunakan sebagai obat.

Tabel 1. Spesies, Famili, Khasiat, dan BagianTumbuhan Obat yang Digunakan Oleh Masyarakat SukuBanggai di Kabupaten Banggai Laut, Provinsi Sulawesi Tengah.

\begin{tabular}{|c|c|c|c|c|}
\hline Nama Spesies & Nama Umum & Familia & $\begin{array}{c}\text { Bagian yang } \\
\text { digunakan }\end{array}$ & Penyakit yang diobati \\
\hline Sericocalyx crispus(L.) Bremek & Keji beling & Acanthaceae & Daun & $\begin{array}{l}\text { Sakit pinggang } \\
\text { Demam }\end{array}$ \\
\hline $\begin{array}{l}\text { Andrographis paniculata } \\
\text { (Brum.f.) Ness }\end{array}$ & Sambiloto & & Daun & $\begin{array}{l}\text { Demam } \\
\text { Maag } \\
\text { Asma }\end{array}$ \\
\hline Amaranthus tricolor $\mathrm{L}$. & Bayam & Amaranthaceae & Seluruh bagian & Paru-paru basah \\
\hline Centella asiatica (L.) Urb. & Pegagan & Apiaceae & Daun & $\begin{array}{l}\text { Maag } \\
\text { Asma }\end{array}$ \\
\hline $\begin{array}{l}\text { Euphorbia tirucalli } \mathrm{L} . \\
\text { Jatropha curcas } \mathrm{L} \text {. }\end{array}$ & $\begin{array}{l}\text { Patah tulang } \\
\text { Jarak pagar }\end{array}$ & Euphorbiaceae & $\begin{array}{l}\text { Batang } \\
\text { Daun, getah }\end{array}$ & $\begin{array}{l}\text { Pembekuan darah } \\
\text { Sakit gigi } \\
\text { Sariawan } \\
\text { Gatal-gatal }\end{array}$ \\
\hline Manihot esculenta Crantz. & Singkong & & Daun & Penurun darah \\
\hline Euphorbia hirta L. & Patikan kebo & & Daun & Batu ginjal \\
\hline Blumea balsamifera (L.) DC. & Pakundalang & Asteraceae & Daun & $\begin{array}{l}\text { Melancarkan haid } \\
\text { Asma }\end{array}$ \\
\hline Mimosa pudica $\mathrm{L}$. & Putri malu & Leguminosae & Daun, akar & Asma \\
\hline Tamarindus indica $\mathrm{L}$. & Asam jawa & & Buah & Melancarkan haid \\
\hline Caesalpinia bonduc (L.) Roxb. & Mata kucing & & Seluruh bagian & $\begin{array}{l}\text { Malaria } \\
\text { Liver }\end{array}$ \\
\hline $\begin{array}{l}\text { Dendrolobium umbellatum (L.) } \\
\text { Benth. }\end{array}$ & Daun tiga & & Daun & Muntah darah \\
\hline Allium ascalonicum $\mathrm{L}$. & Bawang Merah & Amaryllidaceae & Umbi & $\begin{array}{l}\text { Amandel } \\
\text { Sakit pinggang }\end{array}$ \\
\hline Allium sativum $\mathrm{L}$. & Bawang putih & & Umbi & $\begin{array}{l}\text { Kolestrol } \\
\text { Penurun darah } \\
\text { Lemah jantung }\end{array}$ \\
\hline Alpinia galanga (L.) Willd. & Lengkuas & Zingiberaceae & Rimpang & $\begin{array}{l}\text { Panas dalam } \\
\text { Sakit perut }\end{array}$ \\
\hline Curcuma zanthorrhiza Roxb. & Temulawak & & Rimpang & $\begin{array}{l}\text { Sakit pinggang } \\
\text { Rheumatik }\end{array}$ \\
\hline Curcuma sp. & Kunyit & & Rimpang & $\begin{array}{l}\text { Menjaga daya tahan } \\
\text { tubuh } \\
\text { Melancarkan haid } \\
\text { Luka bernanah } \\
\text { Radang usus }\end{array}$ \\
\hline Kaempferia sp. & Kencur & & Rimpang & $\begin{array}{l}\text { Batuk kering } \\
\text { Memperbaiki nafsu } \\
\text { makan } \\
\text { Luka bengkak/memar }\end{array}$ \\
\hline Zingiber officinale Roscoe. & Jahe & & Rimpang & $\begin{array}{l}\text { Batuk } \\
\text { Sakit kerongkongan }\end{array}$ \\
\hline Hyptis capitata Jacq. & $\begin{array}{l}\text { Rumput pago- } \\
\text { pago }\end{array}$ & Lamiaceae & Seluruh bagian & Diabetes \\
\hline $\begin{array}{l}\text { Clerodendrum chinense } \\
\text { (Osbeck.) Mabb. }\end{array}$ & Bungaku & & Daun & Pembekuan darah \\
\hline Ocinum basillicum L. & Kemanagi & & Daun & $\begin{array}{l}\text { Lemah jantung } \\
\text { Menghilangkan bau } \\
\text { badan }\end{array}$ \\
\hline $\begin{array}{l}\text { Orthosiphon aristatus (Blume.) } \\
\text { Miq. }\end{array}$ & Kumis kucing & & $\begin{array}{l}\text { Seluruh bagian, } \\
\text { Daun }\end{array}$ & $\begin{array}{l}\text { Diabetes } \\
\text { Batu ginjal } \\
\text { Rheumatik }\end{array}$ \\
\hline $\begin{array}{l}\text { Plectranthus scutellarioides (L.) } \\
\text { R.Br. }\end{array}$ & Mayana & & Daun & Batuk \\
\hline
\end{tabular}


Khairiyah et al./Galenika Journal of Pharmacy

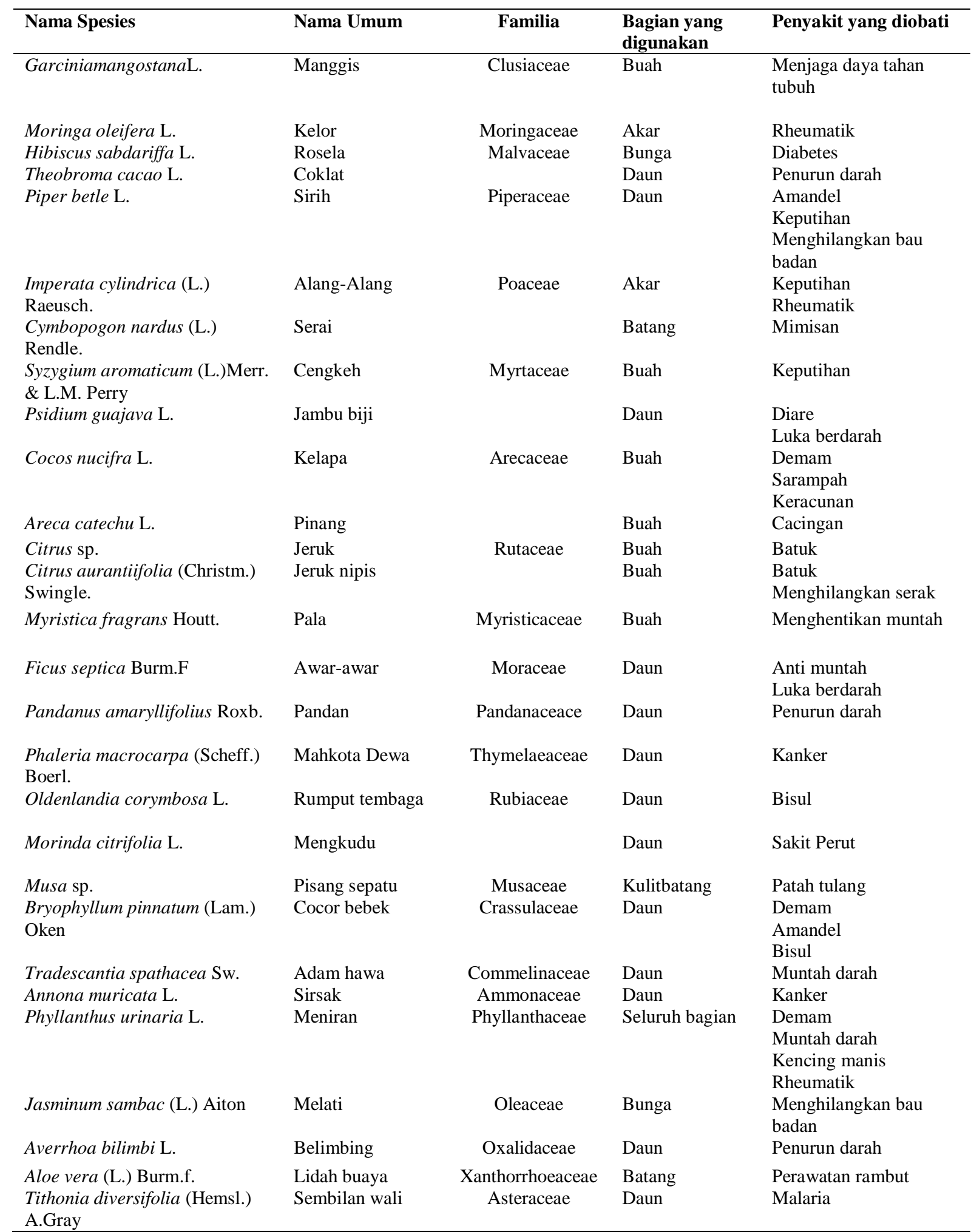

Ket :

Seluruh Bagian (daun, batang, akar) 
Tabel.2. Persentase Bagian Tumbuhan Obat yang Digunakan Oleh Masyarakat Banggai di Kabupaten Banggai Laut, Sulawesi Tengah

\begin{tabular}{lr}
\hline $\begin{array}{c}\text { Bagian Tumbuhan } \\
\text { Yang digunakan }\end{array}$ & Persentase \\
\hline Daun & $49 \%$ \\
Batang & $5 \%$ \\
Buah & $12 \%$ \\
Akar & $3 \%$ \\
Rimpang & $9 \%$
\end{tabular}

\section{Pembahasan}

Berdasarkan hasil wawancara pada 7 informan (sandro), diketahui bahwa terdapat 54 jenis tumbuhan yang digunakan sebagai obat. Masyarakat suku Banggai menggunakan tumbuhan obat sebagai obat tradisional secara turun temurun dari nenek moyang atau orang tua terdahulu. Namun ada pula yang menggunakan tumbuhan tersebut berdasarkan mimpi yang pernah dialami.

Berdasarkan hasil wawancara menunjukkan bahwa masyarakat suku Banggai di Kabupaten Banggai Laut dalam memanfaatkan tumbuhan sebagai obat tradisional menggunakan beberapa bagian dari tumbuhan tersebut. Bagian tumbuhan yang digunakan yaitu daun, buah, batang, kulit batang, akar, bunga, getah, umbi, rimpang dan semua bagian tumbuhan. Bagian tumbuhan yang banyak digunakan untuk pengobatan yaitu daun sebesar $49 \%$.

Berdasarkan jenis penyakitada beberapa cara pengolahan dan penggunaan tumbuhan obat yang dilakukan oleh masyarakat Suku Banggai di Kabupaten Banggai Laut, adapun cara pengolahan tumbuhan obat oleh suku Banggai di Kabupaten Banggai Laut antara lain direbus, ditumbuk, diremas, diperas, diparut, direndam, diseduh, dikonsumsi langsung dan cara penggunaan yang dilakukan yaitu diminum, dimakan, digosok, ditempelkan, dioleskan, dikumur-kumurkan, dibalurkan dan langsung digunakan. Cara penyajian dari tumbuhan obat tersebut disajikan secara tunggal dan dalam bentuk ramuan.

Tumbuhan obat yangdigunakan oleh masyarakat suku Banggai di Kabupaten Banggai Laut tidak hanya digunakan untuk satu atau dua macam penyakit saja, tetapi digunakan untukpengobatan beberapa macam penyakit.Berdasarkan hasil wawancara yang telah dilakukan terhadap 7 informan terdapat

\begin{tabular}{lc}
\hline \multicolumn{1}{c}{$\begin{array}{c}\text { Bagian Tumbuhan } \\
\text { Yang digunakan }\end{array}$} & Persentase \\
\hline Umbi & $4 \%$ \\
Seluruh Bagian Tumbuhan & $10 \%$ \\
Kulit Batang & $2 \%$ \\
Getah & $3 \%$ \\
Bunga & $4 \%$
\end{tabular}

beberapa jenis penyakit yang dapat diobati menggunakan tumbuhan obat oleh masyarakat suku Banggai Kabupaten Banggai Laut. Diantara jenis penyakit tersebut terdapat 10 macam penyakit kronik,3 penyakit menular, 27 penyakit tidak menular dan 5kegunaanuntuk perawatan kesehatan tubuh. Berikut beberapa contoh cara pengolahan tumbuhan obat oleh suku Banggai

1. Diabetes

MenurutInforman 1, rumput pagopago (Hyptis capitata Jacq.) digunakan untuk mengobati penyakit diabetes. Diolah dengan cara seluruh bagian rumput pagopago direbus dalam 2 liter air sampai mendidih, disimpan lalu air hasil saringannya diminum 3 kali sehari.

2. Tekanan darah tinggi

Menurut Informan 3, daun coklat (Theobroma cacao L.) digunakan untuk mengatasi atau menurunkan tekanan darah tinggi. Pucuk daun coklat sebanyak 10 lembar direbus dalam 1 liter air sampai mendidih dan diminum airnya 3 kali sehari.

3. Kanker

Menurut Informan 5, daun sirsak (Annona muricata L.) digunakan untuk mengobati penyakit kanker. Daun sirsak yang sudah tua diolah dengan cara merebusnya dalam 1 liter air sampai tinggal 1 gelas, kemudian didinginkan lalu diminum 2 kali sehari sampai kankernya hilang.

4. Asma

Menurut Informan4, pakundalang (Blumea balsamifera (L) DC.) dapat digunakan untuk mengobati asma, diolah dengan cara daun pakundalang direbus sampai mendidih, disaring lalu didinginkan. Diminum 2 kali sehari dengan di tambahkan gula merah. 
5. Liver

MenurutInforman 3, penyakit liver dapat diobati dengan tumbuhan mata kucing (Caesalpinia bonduc (L.) Roxb.)dengan cara mata kucing diseduh dengan air panas lalu diminum 1 kali sehari

6. Paru-Paru Basah

Menurut Informan 6, bayam (Amaranthus tricolor L.) dapat digunakan untuk mengobati penyakit paru-paru basah. Bayam diolah dengan cara semua bagian tumbuhan dicuci bersih, kemudian direbus dengan air 3 gelas hingga menjadi 1 gelas, lalu disaring. Air hasil saringan diminum 3 kali sehari setelah makan.

7. Demam

Menurut Informan 5, air kelapa (Cocos mucifra L.) dapat mengatasi demam. Air buah kelapa yang masih muda diminum sebanyak 1 gelas dalam sehari sampai demamnya hilang.

8. Sakit gigi

Menurut Informan 2, sakit gigi dapat diobati dengan tumbuhan jarak pagar atau dalam bahasa banggai dikenal dengan nama balacai (Jatropha curcas L.). Daun balacai diremas-remas dengan air, tambahkan garam secukupnya lalu dikumur- kumurkan.

9. Keputihan

Menurut Informan 1 untuk mengobati masalah keputihan pada wanita dapat digunakan ramuan dari daun papaya (Carica papaya L.), akar alang-alang (Imperata cylindrica (L.)Raeusch.) dan buah cingkeh (Syzygium aromaticum (L.) Merr.\&L.M. Perry.). 1 lembar daun pepaya muda, 4 akar alang-alang dan 5 buah cengkeh yang telah dikeringkan dicuci bersih, diiris-iris kemudian direbus dengan 4 gelas air hingga menjadi 3 gelas. Lalu diminum 3 kali dalam sehari.

10. Menghentikan muntah

Menurut Informan 7, daun awar-awar atau dalam bahasa Banggai dikenal dengan nama bulobundung (Ficus septica Burm.F.) dapat mencegah dan mengatasi muntah saat melakukan perjalanan. 1 lembar daun bulobundung diletakkan ditempat duduk dan diduduki ketika sedang dalam perjalanan.
11. Muntah darah

Menurut Informan 2, untuk mengobati penyakit muntah darah digunakan daun tiga (Dendrolobium umbellatum (L.) Benth.).Daun tiga dicuci bersih kemudian direbus dengan air 3 gelas hingga menjadi 1 gelas.Air rebusan disaring kemudian diminum 1 kali sehari.

12. Malaria

Menurut Informan 3, penyakit malaria dapat diobati dengan menggunakan mata kucing (Caesalpinia bonduc (L.) Roxb.). Diolah dengan cara mata kucing diseduh dengan air panas lalu diminum 2 kali sehari.

13. Pembekuan darah

Menurut Informan 5, daun bungaku (Clerodendrum chinense (Osbeck) Mabb.) digunakan sebagai obat pembekuan darah. Diolah dengan cara daun bungaku ditumbuk halus dibalurkan dibagian tubuh yang mengalami pembekuan darah. Perawatan kesehatan tubuh

\section{Melancarkan Haid}

Menurut Informan 4, daun pakundalang(Blumea balsamifera (L.) DC.) digunakan sebagai pelancar haid. Diolah dengan cara daunnya direbus dalam 1 liter air sampai mendidih lalu dinginkan. Sebelum diminum dicampurkan dengan gula merah.Minum dalam kondisi hangat 2 kali sehari.

15. Penambah nafsu makan

Menurut Informan 1, kencur digunakan untuk memperbaiki nafsu makan. Kencur (Kaempferia sp.) digunakan dengan cara direbus dalam 1 liter air sampai mendidih ditambahkan gula secukupnya kemudian air basil rebusan diminum 1 kali sehari.

\section{DAFTAR PUSTAKA}

Bodeker. G. (2000). Indigenous Medical Knowledge : The Law and Politics of Protection : Oxford IntelektualProperty Research Center Seminar in St. Peter's College, $25^{\text {th }}$ January 2000. Oxford.

Dianto., I. (2015). Studi Etnofarmasi Tumbuhan Berkhasiat Obat Pada Suku 
Khairiyah et al./Galenika Journal of Pharmacy

Kaili Ledo di Kabupaten Sigi Provinsi Sulawesi Tengah.Skripsi. Universitas Tadulako .Palu

Notoatmodjo., S. (2002). Metodologi Penelitian Kesehatan.PT Rineka Cipta. Jakarta.
Sugiyono. (2007). Memahami Penelitian Kualitatif, Alfabeta, Bandung. 